\title{
HISTORY
}

\section{СТРАТЕГИЯ КНР В ДЕЯТЕЛЬНОСТИ И РАЗВИТИИ ВОЗ}

\author{
Хуан Куньпэн, \\ аспирант ФМО, Белорусский государственный университет, г. Минск, Беларусь
}

DOI: https://doi.org/10.31435/rsglobal_ijitss/31052020/7062

\section{ARTICLE INFO \\ Received 20 March 2020 \\ Accepted 11 May 2020 \\ Published 31 May 2020 \\ KEYWORDS \\ China's activities in WHO; development; strategy.}

\begin{abstract}
At present, the influence of globalization is especially noticeable in the economic, political, religious and cultural fields. However, the lack of boundaries in diseases and the value of health for all nations are determined by the fact that the development of global health management will not be limited by anti-globalization tendencies and campaigns. Global health management is one of the most important issues in the context of global governance, both now and in the future. WHO, as the world's largest official health organization, is of particular importance. For China as a developing country, strengthening its representation in the World Health Organization, as well as integration into the global health management system, are seen as leading strategic objectives in the framework of China's participation in global governance. Relevant events of the World Health Organization define the strategy for health diplomacy in China.
\end{abstract}

Citation: Huang Kunpeng. (2020) The PRC Strategy in the Work and Development of WHO. International Journal of Innovative Technologies in Social Science. 4(25). doi: 10.31435/rsglobal_ijitss/31052020/7062

Copyright: (C) 2020 Huang Kunpeng. This is an open-access article distributed under the terms of the Creative Commons Attribution License (CC BY). The use, distribution or reproduction in other forums is permitted, provided the original author(s) or licensor are credited and that the original publication in this journal is cited, in accordance with accepted academic practice. No use, distribution or reproduction is permitted which does not comply with these terms.

ВО3 является одним из важных международных отношений Китая. Поэтому изучение стратегии и развития КНР во Всемирной организации здравоохранения (ВОЗ) может лучше понять внешнюю политику Китая и улучшить систему здравоохранения в КНР. В этой статье рассматривается история создания ВОЗ и роль Китая во Всемирной организации здравоохранения, участие в деятельности ВОЗ и т.д. для решения внешней политики КНР в ВОЗ.

Исторический контекст создания Всемирной организации здравоохранения (ВО3)

Сохранение здоровья человека является общей заботой международного сообщества ещё c XIX века. Болезни, не признающие границ; микробы, не делающие различия между национальностями; предотвращение распространения вирусных инфекций - это международные проблемы, равно как и поиск методов и технологий профилактики и лечения болезней, выраженные в непрестанном стремлении человечества с древнейших времён. Здоровье всего человечества тесно связано с мировым здравоохранением. Ни одна страна не может справиться с этими проблемами в одиночку без участия мирового сообщества. В связи с этим вопросы профилактики инфекционных заболеваний и создание учреждений международной организации здравоохранения встали перед международным сообществом ещё в XIX веке. В 1907 году в Париже было создано Международное управление здравоохранения, International Health Office [1]. Международная организация здравоохранения (BО3) была образована одновременно с Лигой Наций в 1920 году [2]. На конференции в 1945 году в Сан-Франциско по поводу создания Организации Объединённых Наций, было принято решение о созыве международной конференции по вопросам здравоохранения [3]. Международная конференция по 
здравоохранению, проходившая с 19 июня по 22 июля 1946 года с участием 61 делегата, в последний день работы приняла «Устав» ВОЗ, что означало создание Всемирной организации здравоохранения. 7 апреля 1948 года «Устав ВОЗ» был утвержден 26 государствами-членами Организации Объединенных Наций и вступил в силу в соответствии со статьей 88 Конституции. После этого, 24 июня, в г. Женева (Швейцария) была созвана первая Международная ассамблея по здравоохранению, а также была учреждена и начала свою деятельность Всемирная организация здравоохранения. Миссия Всемирной организации здравоохранения заключается в том, чтобы предоставить людям максимально высокий уровень здравоохранения. По состоянию на май 2017 года ВО3 насчитывает более 193 стран-членов. ВОЗ является руководящим и координирующим органом по вопросам здравоохранения в системе Организации Объединенных Наций. Она играет ведущую роль в вопросах глобального здравоохранения, ставя текущие исследовательские задачи в области здравоохранения, разрабатывая нормы и стандарты, формулируя варианты политики на основе фактических данных, предоставляя техническую поддержку странам, а также отслеживая и оценивая тенденции в области здравоохранения.

На мой взгляд, создание Всемирной организации здравоохранения способствует интеграции мировых ресурсов здравоохранения. Всемирная организация здравоохранения будет эффективно предотвращать широкомасштабное распространение инфекционных заболеваний и эффективно защищать здоровье человека.

\section{Всемирная организация здравоохранения в Китае}

Китай является одной из стран-учредителей ВОЗ. В период с 25 апреля по 26 июня 1945 года в Уставе, принятом на Генеральной Ассамблее в Сан-Франциско, отсутствовало упоминание о гигиене, а также не упоминалось об учреждении международного агентства по здравоохранению. Ши Симинг (Shi Siming), секретарь китайской делегации, возглавляемой Сон Зивен (Song Ziwen) на конференции в Сан-Франциско, заметил это упущение, что привело к появлению Всемирной организации здравоохранения. «Декларация об учреждении международной организации по вопросам здравоохранения», представленная китайцем Ши Симингом и Бразилией по поручению Су Саваха (Su Sawah), заложила основу для создания Всемирной организации здравоохранения. 10 мая 1972 года 25-я сессия Всемирной ассамблеи здравоохранения приняла резолюцию, которая восстановила законное место Китая во Всемирной организации здравоохранения. В последующие годы Китай избирался членом Исполнительного комитета для участия в заседаниях региональных комитетов и подписал меморандум и базовое соглашение с организацией по вопросам здравоохранения и технического сотрудничества. В октябре 1978 года министр здравоохранения Китая и Генеральный директор организации подписали в Пекине Протокол о взаимопонимании в области здравоохранения и технического сотрудничества, ставший важной вехой в истории дружеского сотрудничества между двумя сторонами. В 1981 году ВО3 открыла представительство в Пекине. В 1991 году Чэнь Минжанг (Chen Minzhang), министр здравоохранения Китая, был награжден ВОЗ золотой медалью «Здоровье для всех». Он был первым министром здравоохранения в мире, удостоенным подобной награды.

К настоящему времени Китай и ВОЗ провели свыше 18 координационных и организационных совещаний по вопросам технического сотрудничества; помощь, оказанная ВО3 нашей стране, превышает 96 млн. долларов США [19].

Делегация встретилась с Председателем Генеральной Ассамблеи ООН, Генеральным секретарем $\mathrm{OOH}$ и Генеральным директором Всемирной организации здравоохранения и стала свидетелем подписания между Китаем и ВОЗ документов о сотрудничестве в рамках Меморандума о взаимном сотрудничестве (инициатива «Один пояс, один путь») в области здравоохранения [16].

Заместитель министра иностранных дел Китая Ли Баодун (Li Baodong) отметил следующее: «В настоящее время все страны в мире становятся все более взаимозависимыми. У нас с вами общая судьба и интересы. В то же время международная ситуация остаётся сложной и нестабильной в связи с растущими глобальными вызовами. В ходе этого визита Китай и другие заинтересованные стороны провели углубленный обмен мнениями по таким важным вопросам, как содействие делу мира и развития, укрепление глобального управления, содействие развитию международных инициатив в области здравоохранения и совместное решение глобальных проблем. Визит высоких китайских чиновников способствовал прагматическому сотрудничеству между Китаем и Всемирной организацией здравоохранения [14]. 
После 35 лет беспрецедентного экономического роста, Китай вытащил 500 миллионов человек из нищеты и вошёл в число стран со средним и высоким уровнями дохода, перейдя на более сложный этап своего развития. Китай сосредоточит свое внимание на более справедливом распределении плодов материального достатка, образовавшихся благодаря развитию и процветанию страны, а также сделает больший акцент на развитии человека (в частности, в плане его здоровья). Сегодняшний Китай отличается от страны пятидесятилетней давности как в материальном отношении, так и в отношении технологии и народонаселения. Средняя продолжительность жизни в Китае (76,3 года) [10], беспрецедентный прогресс в достижении ЦРТ(цели развития тысячелетия), почти всеобщий охват базовым медицинским страхованием (95\% населения) и общие расходы на здравоохранение за увеличившиеся за последние 20 лет почти в 40 раз и достигшие 5,6\% от ВВП [11]. Китайцы живут дольше и здоровее, чем 50 лет назад.

Несмотря на эти достижения, по-прежнему существуют определённые различия в показателях здоровья и расходах на душу населения в области здравоохранения между городскими и сельскими районами, между различными группами людей и между различными регионами. Высокие издержки являются основным фактором, препятствующим справедливому доступу к медицинским услугам. 70 миллионов человек до сих пор живут за чертой бедности [11], и примерно около $40 \%$ из этого числа испытывают проблемы, связанные со здоровьем. Быстрое развитие также привело к возникновению новых вызовов. К 2053 году число пожилых людей в Китае достигнет 487 миллионов, что составит $35 \%$ от общей численности населения [12] (13,7\% в 2011 году) [5], при этом свыше 70\% населения будет жить в городах (54\% в 2014 году) [6]. Крупномасштабная урбанизация и повышение благосостояния стали причиной изменений в образ жизни. Ухудшение окружающей среды, старение населения, а также прошлые и текущие модели экономического роста, в значительной степени зависящие от промышленности, усугубили преобразование спектра заболеваний в сторону неинфекционных заболеваний (НИЗ). Неинфекционные заболевания в настоящее время являются причиной 85\% от общей смертности населения Китая [15]. Несмотря на то, что доля инфекционных заболеваний в общем уровне заболеваний в настоящее время невелика, проблемы резистентности к лекарственным средствам (включая туберкулез с множественной лекарственной устойчивостью), распространённость вирусного гепатита В и С стоят на повестке дня Целей развития тысячелетия, также как и СПИД. Вопрос о всеобщем охвате медицинскими услугами и услугами в сфере охраны репродуктивного здоровья не теряет своей значимости как часть усилий по поддержанию общественного здоровья.

Для меняющейся роли Китая необходимо, чтобы ВОЗ реагировала на новые направления и направляла будущее сотрудничество. С учётом анализа текущего состояния здравоохранения Китая и опыта внедрения предыдущего варианта «Стратегии государственного сотрудничества» (State Cooperation Strategy), новая версия стратегического документа о сотрудничестве между Китаем и ВОЗ развила предложения китайского правительства в «Основных положениях плана развития национальной системы здравоохранения (на 2016-2020 годы)», «Рамочной программе ООН по оказанию помощи в целях развития для Китая: Китай (на 2016-2020 годы)», 12-я Общей программы работы (на 2014-2019 годы) ВОЗ и Целях устойчивого развития. Установленные приоритеты также учитывают обязательства, взятые Китаем в качестве государства-члена ВОЗ, и существующее соглашение между ВОЗ и Китаем [7].

Поддерживая инициативы политиков и законодателей, ВОЗ может наилучшим образом использовать свои сравнительные преимущества и максимизировать их ценность; ВОЗ может помочь накопить доказательную базу для проведения изменений в политике, проводить диалоги высокого уровня по важным вопросам здравоохранения; и использовать свою популярность и престиж. В частности, она может воспользоваться интернетом, освещением событий в социальных сетях и изменением отношения людей к расходам на здравоохранение с целью направлять распространение информации об охране здоровья [8].

Китай будет содействовать укреплению здоровья всех своих граждан в сотрудничестве с ВОЗ. Последняя играет всё более важную роль в общей системе здравоохранения в Китае.

По моему мнению, как одна из стран-основателей Всемирной организации здравоохранения, Китай активно учувствует в соответствующих мероприятиях Всемирной организации здравоохранения. Китай представил передовой опыт Всемирной организации 
здравоохранения, эффективно содействует двустороннему интерактивному сотрудничеству, а также улучшает общее медицинское обслуживание в Китае, а также стандарты и общий медицинский уровень, и уровень здоровья граждан Китая.

\section{Роль Китая в глобальном здравоохранении}

На население Китая приходится $20 \%$ всех жителей земного шара. В связи с такой численностью населения меры по улучшению здоровья собственного населения в Китае являются огромным вкладом во всемирную охрану здоровья. Китай принимал активное участие в форуме по международному здравоохранению и развитию в 2010-2012 гг. и пожертвовал 285 млн. долларов США многосторонним агентствам. Китай является членом Исполнительного комитета Всемирной организации здравоохранения, а также членом Глобального фонда для борьбы со СПИДом, туберкулезом и малярией и совета UNAIDS. Китай также активно участвует в формулировании Целей устойчивого развития. В 2015 г. Китае стал местом проведения Пятого «круглого стола» по проблемам Центральной Африки, в рамках которого обсуждались вопросы здравоохранения и рассматривались новые пути сотрудничества между Китаем и Африкой. Особое значение, которое Китай придаёт теме охраны здоровья, также находит своё отражение в выполнении им международных обязательств, таких как Международные медико-санитарные правила (2005 г.), Конвенция ООН о правах инвалидов и Рамочная конвенция ВОЗ по борьбе против табака, которая была частично реализована Китаем в 2005 году[18].

Успешный опыт Китая также может быть использован другими развивающимися странами при формулировании их внутренней политики и решении проблем здравоохранения, с которыми они сталкиваются в рамках программы «Сотрудничество по линии Юг-Юг». Китайское правительство постоянно увеличивает свою техническую и финансовую помощь внешнему миру, особенно наименее развитым странам. Оно помогает этим странам решать их проблемы в области здравоохранения, направляя туда медицинские бригады, передавая безвозмездно медицинское оборудование и медикаменты, строя медицинские учреждения и обучая медицинский персонал. В последние годы сотрудничество распространилось на программы по контролю заболеваниями такими, как борьба с малярией. Китай твердо продемонстрировал своё лидерство на международном уровне в случае с эпидемией лихорадки Эбола в Западной Африке, предоставив свыше 120 млн долларов США в качестве помощи трём западноафриканским странам, которые в наибольшей степени пострадали от вспышки заболевания, и направив около 1200 медиков в район эпидемии. Китайские медицинские специалисты также обучили в общей сложности 13000 местных медицинских работников в девяти африканских странах. С учётом огромного населения в 1,3 млрд. человек и растущей мобильностью последнего Китай играет ключевую роль в глобальной охране здоровья. Китайское правительство активно продвигало внедрение Международных медико-санитарных правил (2005 г.). В качестве примера можно привести своевременное предоставление информации о случаях птичьего гриппа H7N9 в 2013 году, своевременную подготовку национального плана профилактики Эболы в 2014 году и координация деятельности 22 министерств с целью обеспечения того, чтобы из общего количества пунктов пропуска через государственную границу (285 пунктов) в 259 были приняты стандартные требования «Международных медико-санитарных правил». Китай постоянно проводит проверки и усиливает подготовку в связи с угрозой новых и рецидивирующих инфекционных заболеваний. В Китае насчитывается 65 центров сотрудничества ВО3, из которых 59 находятся на материке, и они также способствуют поддержанию международного здравоохранения и безопасности. Основные лекарственные средства и вакцины, производимые в Китае, всё активнее поступают на мировой рынок по доступным ценам [8].

На мой взгляд, недостатками Китая в управлении глобальным здравоохранением являются: нехватка персонала в соответствующих медицинских специалистах, а также неполнота реформ в области здравоохранения, которые ограничивают общее улучшение уровня медицины и здравоохранения в Китае; Преимущества: Традиционный медицинский опыт может быть распространен на весь мир и принести пользу людям всех стран. Китай усиливает подготовку медицинских работников, опираясь на передовой опыт в области медицины и здравоохранения других стран. Китай концентрирует внимание на преимуществах развития народной медицины. Исходя, из всего вышеперечисленного Китай имеет право говорить о глобальном управлении здравоохранением. 


\section{Новый Генеральный директор ВОЗ подтвердил роль Китая во Всемирной организации здравоохранения}

В 2017 году ВО3 впервые приглашена принять участие в саммите G20. Впервые на этом саммите на повестке дня будут стоять такие вопросы, как развитие партнёрства и сотрудничества в странах Африки, иммиграция и общественное здравоохранение. 8 июля сразу после завершения саммита и вступления в должность Генеральный директор ВОЗ д-р Тедрос Адханом Гебрейесус заявил журналистам, что Китай является важным партнёром для развития Африки и что он помогает Африке добиться индустриализации, способствует созданию рабочих мест и внесению значительного вклада в общественное здравоохранение в общемировом масштабе. Г-н Тедрос Адханом сказал, что президент Си продемонстрировал своё желание продолжать содействовать готовности Китая участвовать в решении глобальных проблем, особенно в сфере здравоохранения. Он также сказал следующее: «Ещё одним очень важным моментом, как вы знаете, является подписание Китаем и Всемирной организацией здравоохранения меморандума. Это фактически основано на меморандуме о сотрудничестве между Китаем и ВОЗ в рамках инициативы «Одни пояс - один путь». Я думаю, что вклад, который Китай внесёт в мир посредством инициативы «Одни пояс - один путь» будет огромным. Поэтому я очень хочу работать с Китаем для достижения цели, указанной в этом меморандуме». Генеральный директор Тедрос Адханом считает, что инвестиции Китая в инфраструктуру Африки будут способствовать достижению общемировых целей в области общественного здравоохранения.

Генеральный директор Тедрос считает, что предлагаемый Китаем социальноориентированный рост ведёт к региональной стабильности и мирному развитию.

Тедрос Адханом сказал, что это очень важно, поскольку замкнутый на себе рост создаёт проблему. Социально-ориентированный рост представляет собой чрезвычайную важность на региональном, общенациональном и мировом уровнях. В противном случае, если некоторые люди получают прибыль, а другие страдают от бедности, мирное сосуществование будет труднодостижимо. По словам Тедроса Адханома, «когда случилась вспышка лихорадки Эбола в Западной Африке, отправка медицинских бригад из Китая сопровождалась значительной материально-технической поддержкой, что было очень важным для африканских стран, пострадавших от вспышки Эболы. Мы надеемся, что в будущем Китай продолжит помогать африканским странам в организации системы оповещения о чрезвычайных ситуациях и улучшении их логистических решений и оказания медицинской помощи» [17].

Я считаю, что помощь Китая третьему миру без политических условий в области здравоохранения странам, расположенным вдоль «пояса и дороги», могут укрепить связи с другими странами и увеличить «мягкую силу» Китая.

Всемирная ассамблея здравоохранения (ВАЗ): путь «ежегодного приглашения»

В 2008 году к власти на Тайване вернулась партия Гоминьдан. Политические силы, расположенные по обеим сторонам Тайваньского пролива, установили определённое политическое взаимное доверие на основе общего понимания «Консенсуса 1992 года» [9] и неприятия «независимости Тайваня». Отношения между обеими сторонами Пролива вступили на путь мира и развития, а также участия Тайваня во Всемирной организации здравоохранения. Деятельность специализированных агентств Организации Объединенных Наций (таких, например, как ИКАО) даёт возможность и пространство для нахождения справедливых и разумных решений.

Всемирная организация здравоохранения (ВО3) является специализированным агентством Организации Объединённых Наций, и полное членство в ней предполагает наличие суверенного государства, однако не самоуправляющиеся территории и районы с определёнными полномочиями в области здравоохранения могут стать ассоциированными членами. С 1997 года власти Тайваня активно стремились получить статус наблюдателя во Всемирной организации здравоохранения. ВОЗ не имеет в своей структуре наблюдателей как таковых, подразумевая главным образом наблюдателей во Всемирной ассамблее здравоохранения (ВАЗ)[20]. Положения о статусе наблюдателя приводятся в Параграфе 2 Правиле 3 Правил процедуры Всемирной ассамблеи здравоохранения: «Генеральный директор может приглашать страны, которые подали заявки на членство, способствовать тому, чтобы прилегающие к ним территории становились ассоциированными членами, и такие территории, которые были привлечены к этому процессу, но ещё не стали Странами, принявшими 
Органический закон, направляют наблюдателей на заседания Всемирной ассамблеи здравоохранения (ВАЗ)». Исходя из этого строгого юридического определения, Тайвань не имеет особой возможности стать наблюдателем в ВАЗ. После проведения обсуждения и консультаций между соответствующими сторонами по обе стороны Пролива, Генеральный директор ВОЗ, во избежание нарушения «принципа одного Китая» и разногласий по поводу понятия «два Китая: КНР и Тайвань», в перспективе направит прямое приглашение. Тайвань будет участвовать во Всемирной ассамблее здравоохранения в качестве наблюдателя. 29 апреля 2009 года генеральный директор ВОЗ Чэнь Фэнфужен (Chen Fengfuzhen) обратился с письмом к «Директору департамента здравоохранения Тайваня» Йе Цзиньчуану (Ye Jinchuan), в котором он пригласил Йе Цзиньчуана возглавить делегацию и воспользоваться статусом наблюдателя от имени «Китайского Тайбэя» на 62-ой Всемирной ассамблее здравоохранения 18-27 мая. Одна из основных особенностей приглашения Генерального директора заключалась в том, что Тайвань может посещать ВАЗ в зависимости от конкретной ситуации.

В соответствии с принципом «одного Китая» Тайвань может ежегодно подавать заявку на получение статуса наблюдателя на Всемирной ассамблее здравоохранения, что является подтверждением уважения суверенитета Китая ВОЗ.

Я думаю: нет места для переговоров по вопросам, связанным с «суверенитетом» и «территорией». Китай, как и другие родственные страны, имеет историю деления на территории и бурное развитие экономики. Поэтому, с момента основания Нового Китая, предыдущие китайские лидеры придавали большое значение защите территориальной и суверенной целостности Китая. Будучи независимой и автономной страной, участие Тайваня в соответствующих мероприятиях Всемирной организации здравоохранения является проблемой Китая. У Китая есть возможности и стратегия для решения своих собственных вопросов. Связанные с ВОЗ мероприятия должны проводиться в соответствии с принципом «Единого Китая», что является необходимым условием для соответствующих мероприятий в области здравоохранения.

\section{Мотивация международной деятельности Тайваня со времени вступления в президентскую должность Цай Инвэнь в 2016 году}

Взяв участие Тайваня в ВАЗ в качестве примера, можно сказать, что после прихода Цай Инвэнь к власти на Тайване в 2016 году, активность действий Тайваня сократилась, а «консенсус 1992 года» был положен на полку. В связи с этим власти Тайваня хотели бы продемонстрировать свою самостоятельность, участвуя в ВАЗ и другой деятельности. Общеизвестно, что 10 мая 1972 года ВОЗ приняла резолюцию 25.1: «Тайвань не является ни членом, ни ассоциированным членом, ни наблюдателем Всемирной организации здравоохранения». С приходом к власти Цай Инвэнь Тайвань перестал признавать «Консенсус 1992 года». Материковый Китай отказал Тайваню в участии в деятельности Всемирной организации здравоохранения с тем, чтобы ограничить усиление позиций Тайваня. Причины отказа континентального Китая Тайваню в участии во Всемирной организации здравоохранения являются следующими: (1) Китайская Республика (КР) пала в 1949 году. (2) Китайская Народная Республика является Китаем, и на Земле есть только один Китай. (3) государственный суверенитет Китая распространяется на Тайвань. Тайвань является провинцией Китая, частью территории Китая, а не суверенным государством. (4) В Уставе Всемирной организации здравоохранения оговорено, что для участия Тайваня должны быть разработаны новые правила и новые образцы. (5) Китай не может допустить, чтобы часть его территории принимала участие от любого имени в международной организации, состоящей из суверенных государств [4]. МИД Китая также отреагировало на мотивацию администрации Цай Инвэнь принимать участие в деятельности Всемирной организации здравоохранения. Во-первых, ВОЗ является специализированным агентством ООН и участие в её деятельности могут принимать только суверенные государства. В качестве составной части Китая Тайвань не имеет права участвовать в Всемирной организации здравоохранения, равно как не имеет права в ВАЗ в качестве наблюдателя. Как по Уставу ООН, так и по Конституции, Тайваня не имеет юридической основы для участия в ВАЗ в качестве наблюдателя. Во-вторых, власти Тайваня поощряют некоторые страны выдвигать предложения с участием Тайваня. Их настоящая цель - создать «два Китая» в попытке политизировать проблему здравоохранения, интернационализировать проблему внутренних дел Китая и реализовать свою мечту о разделении политических судеб Китая. Эта практика не только серьезно нарушала международное право, но также вносила помехи в работу Генеральной Ассамблеи и 
способствовала политической конфронтации между государствами-членами. Китайское правительство решительно выступает против присоединения Тайваня к Всемирной организации здравоохранения, что служит поддержке целей Всемирной организации здравоохранения и защищает принцип «один Китай». В-третьих, в рамках принципа «одного Китая» Центральное правительство готово сотрудничать с тайваньскими властями относительно соответствующего участия Тайваня в технической деятельности Всемирной организации здравоохранения (BО3). Китай готов сотрудничать с ВОЗ в целях содействия совместным действиям с экспертами Тайваня в области обмена технологиями в организации. Если Тайвань нуждается в технической поддержке со стороны ВОЗ, Центральное правительство будет активно поддерживать её предоставление, если к нему обратятся с соответствующей просьбой [13].

Я думаю: соответствующие мероприятия Тайваня во Всемирной организации здравоохранения с 2016 года явно направлены на то, чтобы некоторые страны использовали Тайвань в качестве пешки, чтобы сдерживать развитие Китая и пытаться расколоть территорию Китая. Эти попытки неизбежно потерпят неудачу. Любое вмешательство в нарушение территории и суверенитета Китая потерпит неудачу. Развитие здравоохранения в Тайване, и в Китае, является целью китайского народа. По принципу «одного Китая» все проблемы по обе стороны пролива могут быть решены.

Как международная организация ВОЗ играет ключевую роль в профилактике инфекционных заболеваний и борьбе с ними, а также в предотвращении международных кризисов в здравоохранении. Китай рассматривает Всемирную организацию здравоохранения в качестве одного из важнейших направлений развития двусторонних отношений и принимает активное участие в деятельности организации. Как крупнейшее развивающееся государство Китай на личном опыте столкнулся с проблемами, вызванными отсталой системой здравоохранения, поэтому китайским лидером была выдвинута концепция «Сообщества единой судьбы человечества»: вместе с ВОЗ разрабатывать собственную систему медицинского обеспечения, оказывать помощь бедным регионам, таким как Африка, внося важный вклад в предотвращение пандемий инфекционных заболеваний. Китай усвоил организационную систему ВОЗ в качестве собственного кодекса поведения и осуществляет медицинскую помощь отсталым регионам по программе «Один пояс один путь» под знаменем ВОЗ. Приобретение Тайванем статуса наблюдателя Всемирной ассамблеи здравоохранения основывается на принципе «одного Китая», который возвращается к «Консенсусу 1992 года», составляющему интересы суверенитета Китая. Национальная самобытность и интересы Китая определяют его работу и стратегии во Всемирной организации здравоохранения.

\section{ЛИТЕРАТУРА}

1. Albert S. Lyons, Heath guidance for better heath. Part I: Medical history - the twentieth century, L'Office International d'Hygiene Publique; 2018 - http://www.healthguidance.org/entry/6356/1/Medical-History--TheTwentieth-Century-Part-1.html

2. League of Nations Chronology: https://www.unog.ch/80256EDD006B8954/(httpAssets)/3DA94AAFEB9E8E7 6C1256F340047BB52/\$file/sdn_chronology.pdf от 08.01.2018г.

3. Hans von Mangoldt\&Volker Rittberger eds., The United Systems and Its Predecessors (Oxford University Press,1997), Vol.I, p.1042. World Health Oganization, "WHO in 60 Years: a chronology of public health milestones," http://www.who.int/features/history/WHO-60th-anniversary-chronoligy.pdf

4. The Taiwan Affairs Office and The Information Office of the State Council, People's Republic of China, White paper on Taiwan Issue, "The One China Principle and the Taiwan Issue," February 21, 2000.

5. The current situation, characteristics, causes of and opportunities presented by the aging population in China in 2015. http://www.chyxx.com/news/2015/0402/309483.html. accessed on 1 March 2016 от 08.01.2018г.

6. World urbanization prospects, department of Economic and Social Affairs, United Nations 2014 http://esa.un.org/unpd/wup/Highlights/WUP2014Highlights.pdf accessed on 29 February 2016 от 08.01.2018г.

7. WHO China statistical profile - http://www.who.int/gho /chn.pdf?ua=1 accessed on 29 February 2016 от 08.01.2018 г

8. Китай - ВОЗ: стратегия национального сотрудничества (2016-2020 годы). 2016 год, Пекин. [Электронный pecypc]. - Режим доступа: http://www.gov.cn/guowuyuan/vom/201603/24/content 5057354.htm. Дата доступа: 08.01.2018.

9. Консенсус 1992 года "по оригиналу, 6 ноября 1992 года. [Электронный ресурс]. - Режим доступа: https://www.liuxue86.com/a/2911364.html. Дата доступа: 08.01.2018. 
10. Национальное бюро статистики Китая. Статистическое коммюнике 2015 года “Национальное экономическое и социальное развитие". [Электронный ресурс]. - Режим доступа: http://www.stats.gov.cn/tjsj/zxfb/201602/t201602291323991.html. accessed on February 2016. Дата доступа: 08.01.2018

11. Национальное бюро статистики Китая. Китайский статистический ежегодник 2015. Китайский статистический издательский дом, р. 206.74-774

12. Ву Юшао и др. Белая книга по проблемам старения: доклад о развитии стареющей промышленности Китая (2014). Общественные науки Academic Press, 2014.

13. МИД направил свой комментарий на разочарование Китая предложением Тайваня на Всемирной ассамблее здравоохранения. Xinhua, 18 мая 2004 г. [Электронный ресурс]. - Режим доступа: http://news.sina.com.cn/c/2004-05-18/08582558732s.shtml. Дата доступа: 08.01.2018

14. Новогодняя дипломатия открылась в большом значении. Ежедневная газета за рубежом, 12 января 2017 года. [Электронный ресурс]. - Режим доступа: http://paper.people.com.cn/rmrbhwb/html/201701/12/content_1743055.htm. Дата доступа: 08.01.2018

15. Китай СДС · Китайский план профилактики и контроля заболеваний (2012-2015 гг.) [Электронный pecypc]. — Режим доступа: http://www.chinacdc.cn/en/ne/2012071t2012072564430.html accessed on 29 February 2016. Дата доступа: 08.01.2018

16. Список достижений саммита “Один пояс, один путь” 2017-05-16. [Электронный ресурс]. - Режим доступа: http://www/fmprc.gov.cn/web/zilia_674904/1179_674909/t1461873.shtml. Дата доступа: 08.01.2018

17. Интервью Генерального директора ВӦЗ: Китай вносит свой вклад в развитие общественного здравоохранения в мире. CCTV, 9 июля 2017 года. [Электронный ресурс]. - Режим доступа: http://www.fmprc.gov.cn/zflt/chn/jlydh/mtsy/t1476540.htm. Дата доступа: 08.01.2018

18. Внедрение Международных медико-санитарных правил $<2005>$. [Электронный ресурс]. -2018 . - Режим доступа: http://apps.who.int/gb/ebwha/pdf_files/WHA69/A69_20-ch.pdf. Дата доступа: 08.01.2018

19. Всемирная организация здравоохранения. [Электронный ресурс]. - 2018. - Режим доступа: https://baike.baidu.com/item/\%E4\%B8\%96\%E7\%95\%8C \%E5\%8D \%AB $\%$ E7\%94\%9F\%E7\%BB $\% 84 \%$ E7 \%BB\%87/483426?fr=aladdin. Дата доступа: 08.01.2018

20. Правила процедуры Всемирной ассамблеи здравоохранения. [Электронный ресурс]. - 2018. - Режим доступа: https:/wenku.baidu.com/view/b1317af54693daef5ef73da4.html. Дата доступа: 08.01.2018 